\title{
Steering through the medical maze
}

$\mathrm{C}$ all them the product of multiplying complexities. So convoluted is the maze of American medicine that it's becoming an essential condition that patients obtain help to negotiate the health system.

Increasingly, they're turning to patient navigators to steer them through the shoals of intervention and paperwork. Originally established in the early 1990 s as a means of helping minorities and economically disadvantaged people gain access to cancer treatment, navigators are now being sought, and hired, for any and all manner of medical treatments, and even for treatment obtained at specific hospitals.

In fact, navigators are becoming an industry unto themselves, leading to concerns that the United States needs some measure of regulatory oversight to determine who should be entitled to declare themselves a navigator, and what their roles and responsibilities should be.

From a patient's perspective, the need for a navigator is becoming all but self-evident, says Joan Ferrin, an American citizen who hired a private patient navigator to guide her sister through treatment for obsessive-compulsive disorder and Tourette syndrome.

"It's hard when you have a complicated illness and every time you go to a different doctor or try to move forward, you find yourself on the edge of a cliff," says Ferrin. With a navigator, "you have another way of climbing up the situation little by little so you can get to the next doctor, figure out the next questions."

It isn't just minorities and the economically disadvantaged who now need help to negotiate the waters of American health care, says Elizabeth Russell, founder and president of Patient Navigator LLC, a private navigation company. Over the last decade, "American health care [has] become more and more dysfunctional, expensive, inefficient, replete with medical error, just downright scary."

The system is "fragmented," adds Russell, who established the firm in 2004, when her 2-year-old daughter was

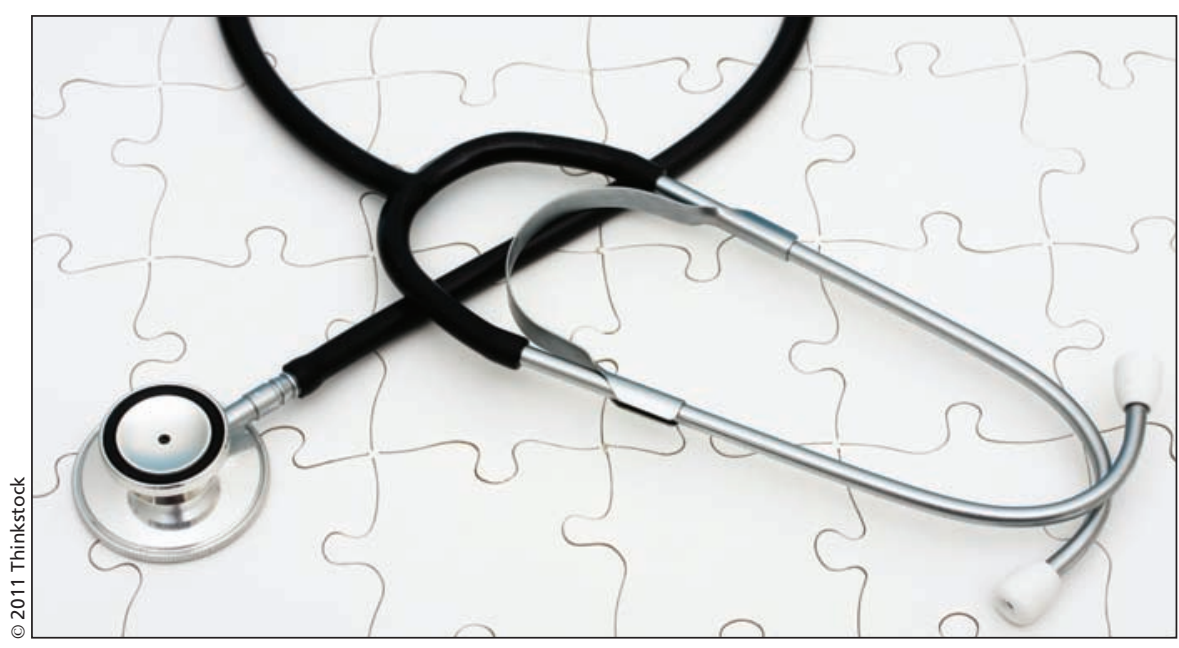

The fragmented health care system in the United States can appear like a puzzle to some patients and many need help putting all the pieces together.

diagnosed with a brainstem tumour. "There's nobody helping people with complicated diseases or acute illnesses or cancer put all the pieces together," such as insurance problems, access to the right specialists, making sure test results are conveyed and medication directions properly explained.

Ferrin hired Russell's firm to ensure that her sister got appropriate treatment and that all the ' $i$ 's' were dotted and ' $t$ ' $s$ ' crossed on insurance claims. "Medicaid, Medicare. I didn't know any of that stuff. I would've screwed that up," she says.

Other patients say navigators are equally invaluable in filtering out the mountains of data available in the cyber sea of medical information.

"The Internet is both a great blessing and a great curse. The great blessing is the amount of information and the great curse is exactly the same," says William Roach, who became a Russell client after being diagnosed with a brain tumour. Russell put together a multipage binder for him outlining the merits of existing and experimental interventions, such as the use of DNA from his tumour as a vaccine. "Kind of a little higher tech than a college grad would be aware of," he says.

Russell argues that patient navigators are also saving America money. Patients with uncoordinated care "con- sume a vast majority of the resources so the statistics prove that when someone is coordinating [a patient's] care, how much money can be saved and [there's] better outcomes," she says, citing an analysis produced by a consulting firm, which concluded that Medicaid patients with uncoordinated care represented only $10 \%$ of all patients but accounted for an average of $46 \%$ of drug costs and $32 \%$ of overall medical costs (http://ahca.myflorida .com/Medicaid/deputy_secretary/recent _presentations/medical_home_tf/2009 -10-27/summary_sec_analyses_cost _uncoordinated_care_sept_2009.pdf). That analysis also found that uncoordinated care costs US $\$ 15100$ per patient, as compared with $\$ 3116$ for those whose care is coordinated.

In some respects, patient navigators have taken on the "role that primary carers used to do and we're the coordinators. We're the ones who make sure things don't fall through the cracks because they will."

Among the more common forms of patient navigators now being appointed in the US are ones specific to hospitals. Those are generally nurses who coordinate hospital resources during a patient's stay, and provide them with resources upon discharge. 
Such hospital-based navigators are most common for patients with breast cancer because the cost of hiring them can be absorbed through the millions of dollars raised through fundraising for breast cancer, Russell says. "The idea is catching on. But I certainly wouldn't say anyone with a breast cancer diagnosis would [automatically] be given a navigator."

Barriers to treatment led to the notion of appointing someone to help patients with breast cancer negotiate their way through the system, says the so-called "father" of patient navigation, Dr. Harold Freeman.

Freeman's studies of roughly 600 women with breast cancer seeking treatment at the Harlem Hospital in New York City during the 1970s indicated that roughly $39 \%$ were alive after five years and only $6 \%$ had been diagnosed with early, stage one breast cancer (www.ncbi .nlm.nih.gov/pubmed/2720605).

That led Freeman to help establish two sites at which women could get free breast cancer screenings. But he soon discovered that the sites were only half the solution, as women who were showing abnormalities in their screenings were not seeking follow-up treatment because of financial, cultural or communication barriers. "The thing I later began to call navigation was born out of that experience of how to get people from finding to resolution in a timely manner," he says.

In 1990, Freeman developed the first patient navigation program at Harlem
Hospital, basing it on a community program in which a peer met with a patient to determine whether any barriers existed to following prescribed treatments. Finances were invariably an issue, particularly for those who lacked health insurance, Freeman says.

A subsequent study surveyed 300 women with breast cancer and found that those who received free screening and navigation saw their five-year survival rate rise to $70 \%$ from $39 \%$.

The results formed the basis for the US Congress's decision to pass the Patient Navigator Outreach and Chronic Disease Prevention Act in 2005, which authorized the spending of US\$25 million over five years to set up navigation services in poor and rural communities. There are now about 20 such local programs.

Freeman also argues that navigators are cost-effective.

Not all navigators must be medical professionals, he says. "Ultimately, to be successful and supported by governments and hospitals, navigation needs to be cost-effective so it doesn't make sense to assign a highly trained professional to do a task that can be done by a lay person for example."

A nurse oncologist isn't needed to iron out financial issues, he adds. "There are navigation tasks and phases that can be done quite well by people who don't have professional training."

Still, there appears to be a desire to elevate the status of navigators to that of medical professionals and to that end, the Harold P. Freeman Patient Navigation Institute was created in 2007 to train people from around the world on the nuances of being a patient navigator.

The reality, though, is that navigators in the US are currently unregulated and as a consequence, patients should be wary, Russell says. "There's no single credential, no state-regulated licenser, which means it's important for people to know what they're getting into if they decide to hire someone." While some private firms are offering to certify navigators, that's no guarantee of competence, she adds. "You have to do your homework."

The onslaught of private certification programs has led Russell and other private navigators to form a national association of navigators in hopes of guiding the growth of the industry and ultimately elevating its level of professionalism. The National Association of Healthcare Advocacy Consultants already has roughly 240 members, has crafted a code of ethics, and is now developing a set of practice standards. — Erin Walkinshaw, Ottawa, Ont.

CMAJ 2011. DOI:10.1503/cmaj.109-3973

First of a two-part series.

Part II: Patient navigators becoming the norm in Canada (www.cmaj.ca /lookup/doi/10.1503/cmaj.109-3974).

\section{Backlash against nonconventional therapy guidelines}

$\mathrm{P}$ atient safety and professional ethics may be compromised by proposed Ontario guidelines on how doctors should acknowledge and incorporate alternative therapies in their practices, professional and regulatory bodies charge.

The groups argue that the College of Physicians and Surgeons of Ontario's (CPSO) draft guidelines, Non-Allopathic (Non-Conventional) Therapies in Medical Practice, apply a lower evidentiary bar for measuring the safety and efficacy of complementary medicine therapies and are effectively asking physicians to counsel patients to undertake unscientific health practices.

In panning the guidelines, the groups also argue that physicians will be placed in the position of breaching their duty to provide patients with the best possible care.

CPSO is currently fielding submissions in response to draft guidelines that would compel physicians "to propose both allopathic and non-allopathic ther- apeutic options that are clinically indicated or appropriate" (www.cpso.on.ca /uploadedFiles/policies/consultations/non -allopathic-consultation-draft.pdf).

All nonallopathic therapies that a physician proposes must:

- "have a demonstrable and reasonable connection, supported by sound clinical judgement, to the diagnosis reached;

- possess a favourable risk/benefit ratio, based on the merits of the option, the potential interactions 